\title{
Increase in energy efficiency of the residential building in Russia
}

\author{
Tatiana Meshcheryakova ${ }^{1, *}$ \\ ${ }^{1}$ Moscow State University of Civil Engineering, Yaroslavskoe shosse, 26, Moscow, 129337, Russia
}

\begin{abstract}
In the modern world, great attention is paid to the problems of preserving a comfortable and safe environment for future generations. The notion of "sustainable development" in the world and national economy, which implies such a consistent development, in which the condition of satisfying the needs of present generations is met without sacrificing the opportunities of future generations, has become particularly relevant. This United Nations concept involves a balanced approach to the environment. Undoubtedly, the most important place in this concept is occupied by resources, including energy resources. Taking into account the world trend and orienting national interests, the Government of the Russian Federation fixes the priority directions for the development of science, technology and technology. Among these directions there are following: "Rational nature management", and also "Energy efficiency, energy saving, nuclear energy". The analysis of tools promoting the implementation of the state policy on energy saving, energy efficiency and environmentally sustainable development (regulatory framework, international and Russian standards) has been analyzed. Key problems of energy saving and energy efficiency of the real estate are formulated. Recommendations for increase in energy efficiency of the residential real estate are developed.
\end{abstract}

\section{Introduction}

In the USSR, for a long historical period, the power industry developed along an extensive path. The demands by industry in the electric power were compensated by building new generating capacities. Artificially low tariffs for electricity, heat and other energy resources for consumers did not stimulate energy saving. Therefore, no effective measures have been developed. As a result, by the beginning of the 21 st century, we have received serious energy saving problems in Russia. On the other hand, today our country has huge potential resources which can be effectively used under the assumptions of successful increase in energy efficiency in the industry and the housing and communal services.

In 2008, Presidential Decree No. 889 "On Some Measures to Improve the Energy and Ecological Efficiency of the Russian Economy" defined the goal of reducing the energy intensity of the gross domestic product (GDP) by $40 \%$ after 2020 in relation to the 2007 level. For these purposes, the decree instructs to take measures for the technical regulation of economic sectors aiming to increase energy and environmental efficiency; to prepare a

* Corresponding autour: t.meshcheryakova@,mail.ru 
regulatory framework at the level of federal laws providing for economic mechanisms that encourage the use of energy-saving technologies and forms the responsibility for noncompliance with permissible standards; to provide budgetary allocations for the implementation of energy-saving projects [1]. Also, the Government of the Russian Federation sets the goal to increase the energy efficiency of buildings by $15 \%$ by 2015 and by another $15 \%$ by 2020 .

At the national level, the basic document is Federal Law No.261 of 23.11.2009 "On Energy Saving and Energy Efficiency Improvement and on Amending Certain Legislative Acts of the Russian Federation" (Federal Law No.261 "On Energy Saving"), whose purpose is to create legal, economic and organizational incentives energy saving and energy efficiency. An important place in the regulatory framework was given to the housing sector.

The purpose of the study is to identify reserves for improving the energy efficiency of residential properties under construction and operation.

The subject of the study is the residential real estate sector.

According to the official data of state statistics, the most energy intensive end-users are industrial enterprises and the population. The latest data presented in the energy balance show that industrial enterprises consume 193.9 tons of equivalent fuel as an electricity, 78.2 tons of equivalent fuel as a heat energy; the population consumes 53.0 tons of equivalent fuel as electricity, 57.2 tons of equivalent fuel as a heat energy [2].

The subject of the research is the process of increasing in the energy efficiency of residential buildings.

To achieve this goal, the following tasks have been accomplished in the course of the research:

- analysis of energy costs of residential real estate;

- analysis of existing regulatory and legal documents, Russian and international standards, which are implementing the state policy on energy conservation and energy efficiency of residential real estate;

- analysis of the list of the best decisions of technologies and possible energy-saving measures for apartment blocks;

- analysis of key problems of energy saving and energy efficiency of real estate;

The recommendations for improving the energy efficiency of residential properties have been developed.

\section{Materials and methods}

The analytical part of the study is based on information from official data of the Federal State Statistics Service, as well as data from federal regulations such as: the Federal Law \# 261 of 23.11.2009 "On Energy Saving"; the Russian Government Decision \# 18 of 252.01.2011 "On Approval of the Rules for Implementing Energy Efficiency Requirements for buildings, structures, requirements and rules for determining the class of energy efficiency of apartment buildings"; the Order of the Ministry of Construction of the RF \# 399 / pr of 06.06.2016 "On approval of the rules for determining the class energy efficiency of apartment buildings".

In addition to energy efficiency, the issues of the ecological compatibility of residential real estate are considered. The following "green standards" actively used in practice are analyzed: the American certification system Leadership in Energy and Environmental Design (LEED), the British certification system British Building Research Establishment Environmental Assessment Method (BREEAM), the German certification system German Sustainable Building Council (DGNB), the Russian certification system STO NOSTROY 2.35.4-2011, Russian certification system - SDS «RUSO».

The research uses such scientific methods as: analysis and synthesis, system approach, logical method of knowledge of the domain, logical and graphical methods. 


\section{Results}

Energy efficiency is a characteristic that reflects the rational use of energy resources. A more ample concept is given in the key document on energy saving and energy efficiency improvement of Federal Law No.261 "On Energy Saving". It is necessary to distinguish between the concept of energy efficiency and energy saving.

Energy saving is the implementation of organizational, legal, technical, technological, economic and other measures aimed to reducing the amount of energy resources used under conditions of preserving the corresponding beneficial effect from their use.

Thus, high energy efficiency indicators can be achieved through effective energy saving (energy-saving measures).

Let's note conceptual provisions concerning the normative-legal documents regulating the questions associated with increase of energy efficiency of apartment houses.

On the instructions of the Government of the Ministry of Regional Development of the Russian Federation, a list of specific energy saving measures for mandatory use was developed (Order of the Ministry of Regional Development of the Russian Federation No. 262 of 28.05.2010). The order provides an exhaustive list of minimally necessary practical measures that allows achieving the indicated energy efficiency indicators, especially for multi-apartment houses of mass building series: increase in the heat transfer resistance of external enclosing structures; replacement of windows with more energy efficient ones; using equipment of heating systems with thermal units with automatic control; application of heat recovery devices for exhaust air; equipment for heat meters, etc.

The procedure for assigning and confirming the energy efficiency class of MultiApartment Houses (MAH) is specified in the Order \# 399 of the Ministry of Construction of the Russian Federation of 06.08.2016 (which came into force on 21.08.2016). The innovation was not a surprise, since work on the draft Order was conducted for many years. Consider the forerunner of this document. The rules for determining the energy efficiency class of multi-apartment buildings establish basic values for the specific annual consumption of energy resources in multi-family residential buildings, as well as the requirements for the introduction of key energy-efficient technologies for certain classes of energy efficiency.

In 2011, the Russian Government issued the Resolution \# 18 "On Approving the Rules for Establishing Energy Efficiency Requirements for Buildings, Structures, Structures and Requirements for the Rules for Determining the Energy Efficiency Class of MAH". The requirements of energy efficiency are to be applied in the design, expertise, construction, commissioning and operation of the buildings that have been built, reconstructed or overhauled, buildings, structures equipped with heat-consuming installations, electric receivers, water-separating devices and (or) devices for the use of natural gas, with a view to providing consumers with energy resources and utilities.

In the same year, the Order of the Ministry of Regional Development of the Russian Federation \# 161 "On Approval of the Rules for the Determination of Energy Efficiency Classes of Many and Requirements to the Index of the Energy Efficiency Class of MAH, located on the facade of the MAH" was issued. It is important to note that the latter document is not longer in validity, since in 2016 there came out previously issued RF Ministry of Construction the Order \# 399 [3].

In accordance with the resolution approved by the Government of the Russian Federation \# 1038 of 18.11.2013, the Ministry of Construction of Russia is the federal executive body responsible for developing and implementing state policy and regulatory and legal regulation in the sphere of ensuring the energy efficiency of buildings, structures and structures. To analyze the general state of energy conservation and to improve energy efficiency in housing and communal services, the following specific indicators of energy consumption were used, calculated on the basis of indicators of the form of the federal statistical observation (Form \# 
22 - Housing Information on the Work of Housing and Communal Services in the Conditions of Reform), as well as official statistical information on the population: a Specific water consumption by the population, $\mathrm{m} 3$ per person; a specific heat consumption in multiapartment houses, Gcal / $\mathrm{m} 2$; a Specific electricity consumption for common house needs in multi-apartment residential buildings, $\mathrm{kW} \bullet \mathrm{h} / \mathrm{m} 2$ [4].

We will analyze the dynamics of energy costs for reporting periods for multi-family residential buildings in Russia (Figure 1):

a)

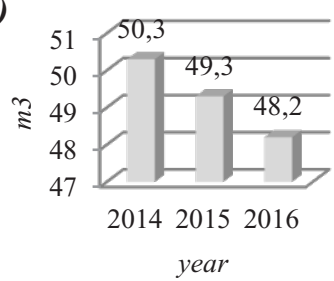

b)

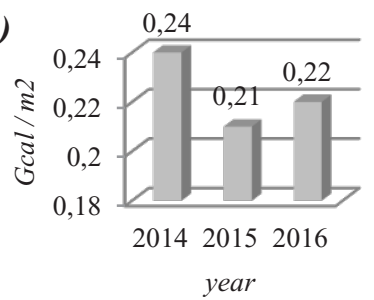

c)

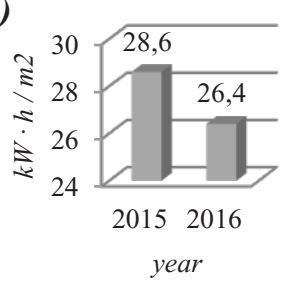

Fig. 1. Dynamics of energy consumption in multi-apartment residential buildings in Russia (a - specific water consumption by population according to Rosstat, $\mathrm{m} 3$ per person; $\mathbf{b}$ - specific heat consumption in MAH according to Rosstat, Gcal / m2; c - specific consumption of electrical energy, $\mathrm{kWh} / \mathrm{m} 2$ ).

The presented data are evident on the tendency of decrease in specific water consumption by the population: from 2014 to 2016 this indicator decreased by $4 \%$ and amounted to 48.2 $\mathrm{m} 3$ per person. Considering separate regions, it should be noted that the reduction in the indicator from 2014 to 2016 was observed in all federal districts of the Russian Federation with the exception of the Southern and North-Caucasian Federal Districts [5, 6].

Specific consumption of heat energy in residential apartment buildings in 2016 increased by $4 \%$ and amounted to $0.222 \mathrm{Gcal}$. In many respects, such dynamics may be due to the fact that in 2015 in most regions of the Russian Federation there was record warm weather in winter. The lowest specific heat consumption is observed in the South and North Caucasus federal districts. This situation can be caused not only by the policy pursued aimed at energy saving, but also by natural and climatic conditions.

Specific consumption of electricity for general needs in MAH tends to decrease: on the whole, this indicator for 2016 decreased by $7.4 \%$ and amounted to $26.4 \mathrm{kWh} / \mathrm{m} 2$. High values of this indicator are observed in the Central and North-Western federal districts. In part, this can be associated with a large expenditure of electrical energy on the power load caused by a higher altitude MAH.

At present, the system of accounting for energy efficiency requirements in the development and approval of national standards and codes of practice in the construction of buildings, structures, structures and overhaul is not formed. An important step in harmonization with the world development in the field of "green" construction of multiapartment residential buildings is the developed standard STO NOSTROY 2.35.4-2011 and complementing it with STO NOSTROY 2.35.68-2012 [7, 8, 9]. These standards, among other things, served as the basis for the first national standard in this field. GOST R 549642012 "Conformity assessment. Environmental requirements for real estate "[7]. The environmental requirements set forth in GOST R 54964-2012 are grouped in nine categories: "Environmental Management"; "Infrastructure and quality of the external environment"; "Quality of architecture and layout of the object"; "Comfort and ecology of the internal environment"; "Quality of sanitary protection and waste disposal"; "Rational water use and regulation of stormwater"; "Energy Saving and Energy Efficiency"; "Environmental protection in the construction, operation and disposal of the facility"; "Ensuring the safety of life". 
The creation of the national standard was the result of the adaptation of international standards to the Russian conditions: BREEAM, LEED, and DGNB. At present, the French analogue - the Haute Gualité Environnementale (HQE) standard - is also entering the Russian certification market.

These Russian or international standards should be applied at various stages on condition of compliance with the safety requirements, which are established by technical regulations in the construction sector. The project can be certified at various stages: in the design, construction, reconstruction, and operation of the property.

When constructing "green" real estate objects, all participants in the process can have advantages: investors, designers, architects, developers, contractors, owners and end-users.

For the investor, the advantages are improving corporate images, reduced risks of asset obsolescence, and reduced risks of rising energy prices. For designers and architects confirmation of their competence and increase in their rating. For the developer - a marketing advantage in the market (increase in the cost of leasing by $2-16 \%$, the cost of sales by 6 $35 \%$ ), raising the capitalization rate, the possibility of attracting additional financing, and securing solvent tenants. For the tenant (end-user) - creating a comfortable environment for residents or employees, increasing labor productivity, saving up to $25-30 \%$ on operating costs, strengthening reputation in the market [10].

All specified documents of normative-legal and regulatory nature are important from the point of view of organization of the very approach to energy saving and energy efficiency of real estate objects [11]. However, they are truly effective tools only for objects that are at the design stage. First of all, this is due to the fact that the buildings that are already in operation, according to the conducted energy surveys, basically do not meet modern requirements for energy efficiency and environmental friendliness. First of all, it is related to the value of the property. If we consider the objects of new construction, among them the economy class of housing predominates - it has the basic demand. Moreover, real estate objects that were sold on the market for several years and decades ago are not characterized by high characteristics that certainly affect the cost.

Concerning the ecological compatibility, it should also be noted that there is no possibility to ensure compliance with the requirements of the "green" standards of the vast majority of real estate objects that are in the phase of operation. This is due to the fact that objects that are certified according to "green" standards are subject to over-standard requirements.

In view of these arguments, it can be concluded that the issue of considering the approach to improving the energy efficiency and environmental friendliness of residential multiapartment buildings that are subject to major repair and reconstruction is of particular importance. It is this segment that makes up the basic ballast in the actual indicators of the energy intensity of residential real estate and requires effective measures to realize the available energy saving potential.

In order to increase the energy efficiency of residential apartment buildings, an investment mechanism such as an energy service contract (ESC) should be used. A diagram illustrating the mechanism of the ESC is given in Figure 2: 


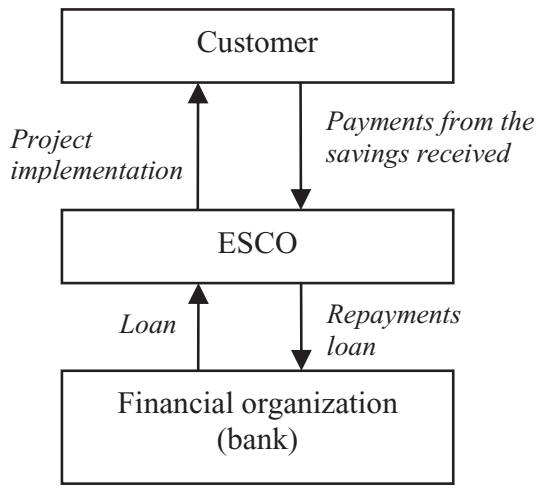

Fig. 2. Mechanism for implementing energy-saving measures using ESC.

At the moment, there are exemplary requirements for an energy service contract, contained in the Order \# 644 / pr of the Ministry of Construction of the Russian Federation of 08.09.2015 "On approval of model conditions for an energy service contract aimed at saving and (or) increasing the efficiency of consumption of public utilities when using common property in an apartment building". In addition, in 2015 the Ministry of Construction of Russia developed a draft federal law "On Amendments to the Housing Code of the Russian Federation (in the part of measures to save energy and improve energy efficiency in relation to the common property of property owners in a multi-apartment building)." The changes are aimed at improving the legal regulation of the procedure for concluding energy service contracts (contracts) in multi-apartment residential buildings. Project

By the law, the adoption of a decision on the conclusion of energy service contracts (contracts) adopted by the general meeting of owners of the premises of a multi-unit residential building is needed.

Here is an approach to the organization of the process of increasing energy efficiency in a multi-family residential building (Figure 3).

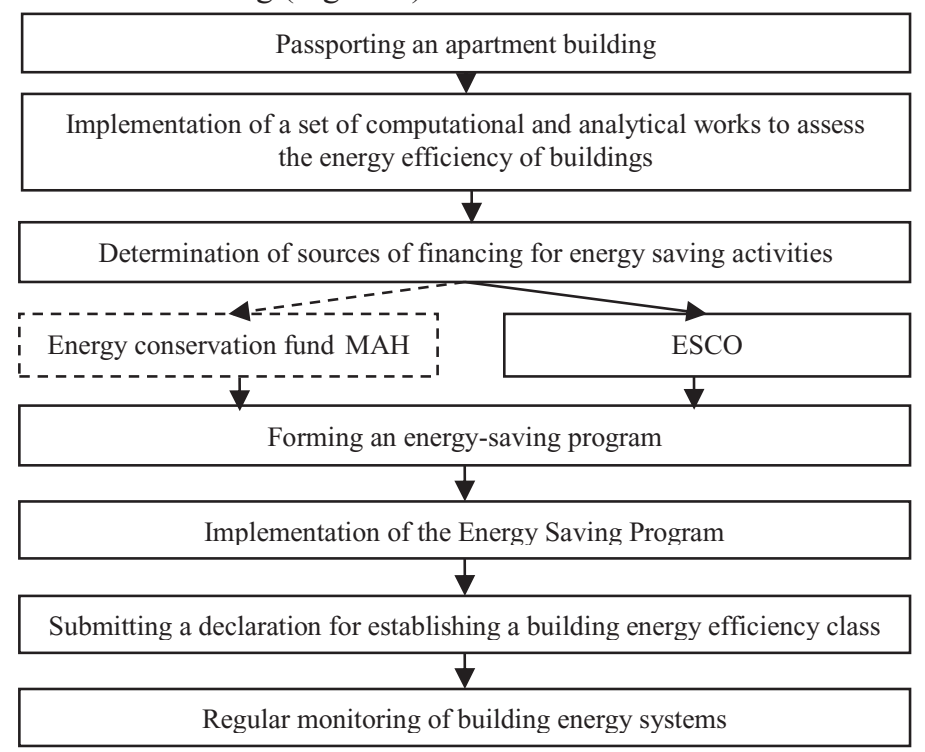

Fig. 3. Approach to improving energy efficiency MAH.

This approach is applicable to buildings that do not relate to new construction sites. It is on this segment that the greatest attention should be paid 
First of all, it is necessary to conduct an energy audit, which will determine the level of energy consumption, as well as the potential for energy saving in an apartment building. It is necessary to divide the process of assigning the energy efficiency class of the building and obtaining an energy passport. At the moment, it is possible to assign an energy efficiency class to a building when submitting a declaration in free form from the owners of the premises of an apartment building or by a person who manages an apartment building to the state housing supervisory authority. The declaration specifies data on the actual values of the annual unit values of energy consumption. After the inspection, the body of state housing supervision issues an act of checking the compliance of the apartment building with energy efficiency requirements and the management company has the right to establish an index of the energy efficiency class on the facade of the building. The filing of a declaration for a building that has been in operation for many years is necessary after the implementation of a program to improve the energy efficiency of a residential building.

\section{Discussion}

The plan of measures to increase the energy efficiency of buildings, buildings and structures provides for the establishment of priority energy efficiency requirements for the purchase of design and survey works, construction, reconstruction and major repair of buildings, procurement of engineering equipment for buildings, taking into account the class of their energy efficiency, including those specified by national standards. All this does not allow the successful development of advanced international experience in a sustainable way. Thus, there are difficulties arises in the dissemination of environmental standards [15].

Considering the actual topic of "green" construction, it should be noted that the relevant market has not yet been properly formed. There is no interest in mass certification of facilities. The least interest is shown by key participants (developers and potential buyers) in the field of residential construction. Consideration of certification as a tool to increase the energy efficiency of MAH is not necessary, in view of the fact that the reconstruction of the secondary residential property market under the environmental standards is not economically feasible.

An important contradiction exists in environmental and energy requirements. In the unification or integration of certain provisions of the national standard for "green" construction in energy efficiency requirements for buildings, structures and requirements for the rules for determining the energy efficiency class of multi-apartment buildings, the implementation of projects of "green" construction will be possible. Thus, it will provide one of the most important aspects of sustainable urban development: resource saving and environmental friendliness.

\section{Conclusions}

About the vast majority of apartment buildings in Russia today, we can say that they are poorly meet the requirements of energy efficiency. This is characteristic not only of the old fund, but also of the new ones. There is a logical explanation for this. The higher the energy efficiency class of a multi-unit residential building (this means quality insulation, installation of expensive plastic windows, etc.), the more expensive it is in construction. But an energyefficient house is much cheaper in subsequent operation. Owners of high-end or very highend energy-efficiency housing spend much less money on maintaining 1 square meter of space than owners living in a low-end energy efficiency class: especially for heating costs in winter or for air conditioning in the summer. Spending once when buying an apartment in an energy-efficient home, or by overhauling the measures to improve energy efficiency, the 
owners will only benefit later. But so far very few take it into account. First of all, this is due to the low level of competence of apartment owners in a multi-unit residential building. With the growth of tariffs for energy resources, the consumer will increasingly pay attention to the operational characteristics of the property.

Concerning the "green" construction, it should be noted that at present the state should become the main interested party in its development. Rating evaluation systems contain not only regulated requirements for structural and engineering solutions for buildings during the construction and operation phases, but also orients and stimulates the solution of a number of government tasks aimed at improving the state of the environmental situation, reducing the negative impact on the environment at all stages of the life cycle of buildings, development of economic profitability of architectural, constructive and engineering solutions, improving the comfort of the human environment, as well as saving mineral and water resources. As an area of active development and introduction of innovations, the "green" construction is an important area of development of technical sciences.

\section{References}

1. Ministry of Energy of Russian Federation, Energy Efficiency (2018)

2. Federal State Statistics Service, Official statistics, Balance of energy resources (2017)

3. Municipal economy and housing and communal services, Classes of energy efficiency of buildings: the procedure for determining and appropriating (2017)

4. Ministry of Energy of Russian Federation, State report on the state of energy conservation and energy efficiency in the Russian Federation in 2016 (2017)

5. Standard of the National Association of Builders "Green building STO NOSTROY 2.35.4-2011 (2011)

6. Standard of the National Association of Builders "Green building STO NOSTROY 2.35.68-2012 (2012)

7. National Standard of the Russian Federation GOST R 54964-2012 "Conformity assessment. Ecological requirements for real estate" (2012)

8. Energy saving, Road map of green building in Russia: problems and prospects (AVOK, 2014)

9. M. Lazarevska, M. Knežević, M. Cvetkovska, N. Ivanišević, T. Samardžioska, A. Trombeva-Gavriloska, Gradjevinar 7/2012(64), 565-571 (2012) ISSN (on line): 13339095; ISSN (printed) 0350-2465

10. P. Petronijević, N. Ivanišević, M. Rakočević, D. Arizanović, Journal of Applied Engineering Science 1(10), 43-48 (2012) ISSN 1451-4117, doi:10.5937/jaes10-1664

11. E. Akimova, D. Knyazev, International Journal of Applied Engineering Research 1, 39387-39394 (2015) 